\title{
Outcome of confirmed symptomatic congenital cytomegalovirus infection
}

\author{
Mary E B Ramsay, Elizabeth Miller, Catherine S Peckham
}

\begin{abstract}
Sixty five neonates with confirmed symptomatic congenital cytomegalovirus infection were followed up prospectively until they were 3 to 4 year of age. Twenty nine children (45\%) had neurological impairment of whom 22 had gross motor or psychomotor abnormalities; in the remaining seven sensorineural deafness was the main abnormality. Infants who had had neurological signs during the neonatal period had a worse prognosis than those who had not, with $16 / 22(73 \%)$ and $13 / 43(30 \%)$ having neurological deficit at follow up, respectively. Our results indicate that the prognosis for infants with symptomatic congenital cytomegalovirus infection is better than previously reported.
\end{abstract}

Cytomegalovirus is the most common cause of congenital infection with an incidence in the United Kingdom of 3/1000 live births. ${ }^{1}$ Over $90 \%$ of children with congenital cytomegalovirus infection have no symptoms at birth and in most there are no adverse effects. ${ }^{1}$ There is insufficient information on outcome in the small proportion of infected infants who present with cytomegalovirus related symptoms at birth. In this paper we describe the outcome in 65 children with symptomatic congenital cytomegalovirus infection and relate prognosis to specific neonatal presentation.

\section{Patients and methods}

Infants with congenital cytomegalovirus infection were identified through reports from laboratories in England and Wales to the Communicable Disease Surveillance Centre (CDSC) between January 1983 and May 1987. The paediatrician in charge was identified through the reporting microbiologist, and sent a detailed questionnaire about the child's clinical condition during the neonatal period and at the time of the last consultation. After two years, a follow up questionnaire was sent to the same clinician or, if hospital care had been discontinued, to the general practitioner. Only infants meeting the following criteria were included. (1) Isolation of cytomegalovirus or detection of specific IgM before 21 days of age (as acquired cytomegalovirus infection is common in early life,${ }^{2}$ children with infections diagnosed beyond this age were not included). (2) Presence of signs consistent with congenital cytomegalovirus infection in the first four weeks of life (infants in whom the only signs were low birth weight, prematurity, or jaundice were not included). (3) Survival beyond the age of 4 weeks.

\section{Results}

During the study period, 142 reports of cytomegalovirus infection in children under the age of 1 month were received from collaborating laboratories. Further information was obtained on 125 of these $(88 \%)$ and permitted exclusion of 19 infants in whom the diagnosis was confirmed between 21 and 28 days of age, 31 asymptomatic infants and eight infants who died in the neonatal period. Of the 67 infants who met the study criteria, two were lost to follow up, and 65 were followed up to a median age of $3 \cdot 5$ years (range $1 \cdot 0-6 \cdot 4)$.

\section{NEONATAL SIGNS AND SYMPTOMS}

Hepatomegaly, splenomegaly, or purpura were reported either alone or in combination in 48/65 of infants (74\%). Neurological signs (other than microcephaly) were less common, and were reported in 22 infants (34\%). These included fits $(n=8)$, cerebral calcification $(n=5)$, and abnormal tone, abnormal movements, or irritability $(n=16)$. Thirteen infants $(20 \%)$ had respiratory problems, which ranged from tachypnoea to the need for ventilation. Most infants had retarded growth or microcephaly, $36(55 \%)$ had a birth weight below the third centile, and $26(40 \%)$ had a head circumference below the third centile for gestation. ${ }^{3}$

CONDITION AT FOLLOW UP

At follow up 36/65 children (55\%) were reported to be normal or to have only a minor abnormality. The latter included two children with mild hypotonia and ataxia, three with conductive hearing loss, and one with both of these problems. There were 29 children $(45 \%)$ with definite neurological impairment. In seven (11\%) the principal deficit was sensorineural deafness (bilateral, $n=6$ and unilateral, $n=1$ ) and three of them also had mild ataxia or awkward gait. The remaining 22 children (34\%), one of whom died aged 2 years, had gross motor or psychomotor problems. These included spastic quadriplegia $(n=9)$, diplegia or hemiplegia $(n=4)$, dyskinetic cerebral palsy $(n=1)$, and severe global psychomotor retardation $(n=6)$. The remaining two children had problems not normally attributed to cytomegalovirus infection-one had bilateral arthrogryphosis of the lower limb joints and one a congenital myopathy. Of these 22 children, 15 were microcephalic at follow up, and although full auditory or visual assessment was not always made, associated sensorineural hearing loss was reported in eight, chorioretinitis in three, and cortical blindness in four.
Correspondence to:

Dr Miller.

Accepted 10 April 1991
PHLS Communicable
Disease Surveillance 61 Colindale Avenue, Mary E B R9 5EQ

Institute of Child Health, London 
Outcome by neonatal presentation. Results are numbers (\%)

\begin{tabular}{|c|c|c|c|c|}
\hline \multirow{3}{*}{$\begin{array}{l}\text { Neonatal } \\
\text { presentation }\end{array}$} & \multirow{3}{*}{$\begin{array}{l}\text { No of } \\
\text { infants }\end{array}$} & \multicolumn{3}{|c|}{ Condition at follow up } \\
\hline & & \multirow[t]{2}{*}{ Normal } & \multicolumn{2}{|c|}{ Definite handicap } \\
\hline & & & $\begin{array}{l}\text { Motor or } \\
\text { psychomotor } \\
\text { problems }\end{array}$ & $\begin{array}{l}\text { Sensori- } \\
\text { neural } \\
\text { deafness }\end{array}$ \\
\hline $\begin{array}{l}\text { Group } 1^{*} \\
\text { Group 2† } \\
\text { Group } 3 \oint \\
\text { All groups }\end{array}$ & $\begin{array}{r}22 \\
35 \\
8 \\
65\end{array}$ & $\begin{array}{rr}6 & (27) \\
22 & (63) \\
8 & (100) \\
36 & (55)\end{array}$ & $\begin{array}{r}14(64) \\
8(23) \\
0 \\
22(34)\end{array}$ & $\begin{array}{ll}2 & (9) \\
59 & (14) \\
0 & \\
7 & (11)\end{array}$ \\
\hline
\end{tabular}

*Infants with neurological signs.

†Infants with hepatomegaly, splenomegaly, or purpura but no neurological signs.

neurological signs.

IOne unilateral.
ØOnts not include

\section{OUTCOME IN RELATION TO NEONATAL}

PRESENTATION

The children were divided into three groups according to neonatal presentation. Those in group 1 presented with abnormal neurological signs (other than microcephaly). Children in group 2 presented with hepatomegaly, splenomegaly, or purpura (either alone or in combination) but had no early neurological signs. Children in group 3 were those not included in groups 1 and 2 who presented with either microcephaly, respiratory problems, or both. At follow up the children in group 1 were at highest risk, and those in group 3 at lowest risk, of subsequent neurological deficit (table).

Of the 26 children who had microcephaly at birth, 16 were still microcephalic and six had a head circumference above the third centile at follow up (in four children the head circumference had not been measured).

\section{Discussion}

This is the largest prospective study of the outcome of symptomatic congenital cytomegalovirus infection so far reported to our knowledge. The aim was to determine the incidence of neurological deficits in children who presented with symptomatic infection in the neonatal period and to relate outcome to neonatal signs and symptoms. The minimum incubation period of acquired infection is 21 days and the study was restricted to infections confirmed before this age. Acquired infection in early life is common, ${ }^{2}$ and where cytomegalovirus is isolated from children after 21 days of age neurological impairment may be wrongly attributed to congenital infection.

The neonatal signs and symptoms of congenital cytomegalovirus infection found in this study were of similar type and incidence to those previously described. ${ }^{4-6}$ The most common presentations were hepatomegaly, splenomegaly, or purpura which were seen in $48 / 65$ infants $(74 \%)$. It was reassuring that 36 children $(55 \%)$ were normal at follow up.
Neurological signs in the neonatal period, however, were associated with a poor prognosis, and 16 of those 22 children $(73 \%)$ had serious subsequent deficits.

The overall prognosis for the children in our study was better than that reported from the United States. ${ }^{4}$ As this earlier study was based on referrals to a specialist hospital, however, it may have included children with more severe neonatal signs. Our study confirms the observations of three smaller studies in which children who had central nervous system involvement during the first year of life had a poor outcome. ${ }^{7-9}$ There have been conflicting reports of the outcome in infants in whom microcephaly was present at birth. ${ }^{710}$ We found that the prognosis for children presenting with either microcephaly or respiratory problems alone was relatively good, and probably similar to that for children who are symptom free during the neonatal period. ${ }^{11} 12$

In conclusion, the findings of this study will permit a more accurate prediction of the outcome of symptomatic congenital cytomegalovirus infections and provide a basis for more confident counselling of parents by paediatricians. As only 19 of the 65 children were over 4 years of age at their last review, continued follow up of this group is planned to detect the possible occurrence of later abnormalities.

We thank the paediatricians, general practitioners, and microbiologists who provided information on their cases, and Mrs Doreen Moffatt and Miss Saroj Valambia for their help with the administration of the study.

1 Preece PM, Pearl KN, Peckham CS. Congenital cytomegalovirus infection. Arch Dis Child 1984;59:1120-6.

2 Peckham CS, Johnson C, Ades A, Pearl K, Chin KS. Early acquisition of cytomegalovirus infection. Arch Dis Child 1987;62:780-5.

3 Gairdner D, Pearson J. A growth chart for premature and other infants. Arch Dis Child 1971;46:783-7.

4 Pass RF, Stagno S, Myers G, Alford CA. Outcome of symptomatic congenital cytomegalovirus infection: results of long term longitudinal follow up. Pediatrics 1980;66: $758-62$.

5 Medearis DN. Cytomegalic inclusion disease. An analysis of the clinical features based on the literature and six additional cases. Pediatrics 1957;19:467-80.

6 Weller TH, Hanshaw JB. Virologic and clinical observations on cytomegalic inclusion disease. $N$ Engl F Med 1962;266: $1233-44$.

7 McCracken GH, Shinefield HR, Cobb K, Rausen AR, Dische R, Eichenwald HF. Congenital cytomegalic incluDische $R$, Eichenwald HF. Congenital cytomegalic inclu-
sion disease. A longitudinal study of 20 patients. Am $\mathcal{F}$ Dis Sion disease. A longitudinal $1969 ; 117: 522-39$.

8 Conboy TJ, Pass RF, Stagno S, et al. Early clinical manifestations and intellectual outcome in children with symptomatic congenital cytomegalovirus infection. $\mathcal{F}$ Pediatr 1987;111:343-8.

9 Bale JF, Blackman JA, Sato Y. Outcome in children with symptomatic congenital cytomegalovirus infection. Foumal of Child Neurology 1990;5:131-6.

10 Berenberg W, Nankervis G. Long-term follow up of cytomegalic inclusion disease of infancy. Pediatrics 1970;46: 403-10.

11 Kumar $M$ L, Nankervis GA, Gold E. Inapparent congenital cytomegalovirus infection. A follow up study. $N$ Engl f Med 1973;288:1370-2.

12 Hanshaw JB, Schiener AP, Moxley AW, Gaev L, Abel V, Scheiner B. School failure and deafness after 'silent' congenital cytomegalovirus infection. N Engl f Med 1976;295: genital cytor. 